\title{
PERSPECTIVES DEMOGRAFIQUES
}

\section{The Demographic Sustainability of Empty Spain}

\author{
Joaquín Recaño, Centre d'Estudis Demogràfics and Universitat Autònoma de Barcelona
}

On 1 January 2016, 60 per cent of Spanish municipalities had fewer than 1,001 inhabitants, occupied 40\% of the country's surface and concentrated barely 3.1\% of the population. Eurostat data situate 19 Spanish provinces among the least dense of the European Union in 2015 . This notable imbalance between population and territory, the basic problem of a vast area in the north and centre of the Iberian peninsula, is characterized by ageing, a relative scarcity of women because of large-scale differential emigration based on gender, and transitory immigration that has been unable to compensate for the demographic outflow which has affected these places since the middle of the twentieth century. The demographic sustainability of this heterogeneous set of municipalities is hanging in the balance. This situation constitutes a major challenge and, moreover, the great diversity of these towns should be borne in mind when it comes to applying public policies.

\section{A LONG HISTORY OF DEPOPULATION}

Although villages in rural areas of Spain are very heterogeneous all of them have, to a greater or lesser extent, suffered the effects of depopulation. While it is nothing new, this situation has again come to the foreground now that the effects of the economic crisis have dashed hopes that immigration would be the panacea for population scarcity in rural areas. The last few years have brought us back to the harsh reality of a demographic space caught between the need for radical transformation and the risk of extinction. Yet things were not always like this. A long,

FIGURE 1. Population pyramids in accordance with typology of rural spaces
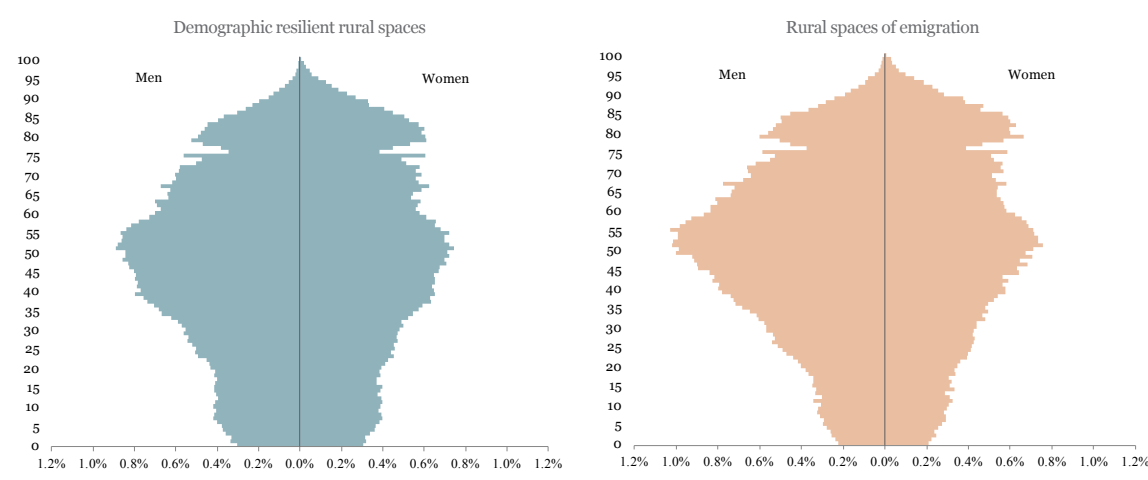

Rural spaces at risk of irreversible depopulation

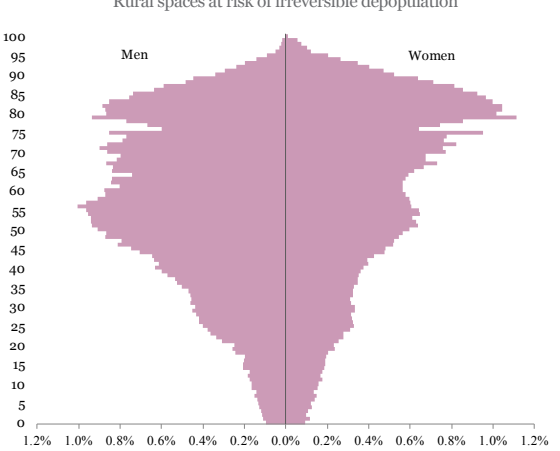

agitated history of the rural population has been the prelude to today's depopulation problems.

In the early years of the twentieth century, one in five of Spain's inhabitants, a total of four million people, lived in municipalities which, in 2016, had 1,000 or fewer inhabitants and the population density was more than 20 inhabitants per $\mathrm{km}^{2}$, which was not a lot less than the overall average for Spain, 37 inhabitants per $\mathrm{km}^{2}$. A century later, the population of these towns had dropped to 1.45 million, almost down to a third, and barely represented 3.1 per cent of that for Spain, while population density was 7.3 inhabitants per $\mathrm{km}^{2}$ by comparison with 92 for Spain. A vast empty world had consolidated in the centre of the peninsula. Yet this long period of 115 years contains a demographic story of rural spaces which is much more complex than these simple data would seem to suggest (Cos and Reques, 2005; Goerlich et al., 2015).

The rural exodus began at the end of the nineteenth century in zones close to urban and industrial centres of Catalonia and the Basque Country but, 
during the first half of the twentieth century, high fertility and declining mortality rates assured continuity and even demographic growth in rural spaces in general. In this period, city populations expanded thanks alone to the demographic surplus of the countryside. The Great Depression of 1929, the Spanish Civil War and the post-war years slowed down emigration from rural areas which, in some parts of the country, reached its demographic peak between 1930 and 1950. After the 1950s, there was a progressive decline in the socioeconomic conditions of rural areas which were unable to compete with the upward social mobility offered by cities. Between 1950 and 1991, these towns lost almost two and a half million inhabitants and were the leading contributors in the rural exodus to urban centres. Without this rural emigration we would not have today's large metropolitan agglomerations of Madrid, Barcelona and Valencia and, within the emigration areas in many regions of the interior, provincial capitals would not have been assured of their demographic sustainability.

\section{THE DEMOGRAPHIC MECHANISMS OF DE- POPULATION}

The process of depopulation is the result of interaction between different demographic phenomena (Vidal and Recaño, 1986). Chief among them is emigration of young people in search of employment and educational opportunities in the cities, which was then followed by a dramatic slump in local marriage markets, aggravated in particular by the greater numbers of women emigrants. The most evident sequela of this is the considerable imbalance between men and women which still persists in numerous rural zones (Figure 1). Emigration, moreover, had a delayed impact as it was the triggering factor of the falling birth rate at the time and also of the future "unbirth" rate, that of those who were not born in these populations because their parents had emigrated. Between the 1960s and the mid-1970s, as the countryside went into demographic decline, Spanish cities recorded the highest-ever number of births, favoured by a fast-rising rate of earlier marriages and a nonstop flow of the young population from country areas. After 1980, a smaller but continuous rural exodus and falling fertility rates countrywide - most steeply in the small towns of the centre and north of the peninsulaonly aggravated depopulation to a previously unimaginable extent.

\section{FACTORS EXPLAINING THE DIVERSITY OF EMPTY SPAIN}

The debate on the demographic sustainability of rural spaces should begin with recognition of the heterogeneity of the almost 5,000 municipalities under consideration. For example, rural areas located in the south and others bordering the Mediterranean and Atlantic coastlines enjoy robust demographic health. In contrast, those in the centre and north of the country are the ones most affected by depopulation. Hence, between 1981 and 2016, 15 per cent of the towns included in the present study showed population increases but in the rest, almost four thousand two hundred towns, there was a significant decline in population. The variety of population dynamics in country towns requires the construction of a typology which includes the aspects that explain these differences.

Table 1: Factors explaining the diversity of country towns in Spain.

\begin{tabular}{|l|c|c|c|}
\hline & Factor 1 & Factor 2 & Factor 3 \\
\cline { 2 - 4 } Correlated variables & Ageing & Emigration & $\begin{array}{c}\text { Proximity to } \\
\text { populated spaces }\end{array}$ \\
\hline Growth rate (1981-2011) & -0.753 & & \\
Average age of population in 2016 & 0.947 & & \\
\hline Size of town's population & & -0.760 & \\
Altitude & & 0.613 & \\
Sex ratio in 2016 & & 0.590 & \\
Intensity of emigration in 2016 & & 0.649 & \\
\hline Population size of surrounding towns & & & 0.830 \\
Density of surrounding towns in 2011 & & & 0.631 \\
\hline
\end{tabular}

Source: Compiled by author on the basis of Goerlich et al., 2015; microdata from Official Population 2016 and data on altitude, surface area and location from the National

The construction of this typology is carried out in two phases. In the first, on the basis of a statistical procedure called Factor Analysis, the factors are identified as groupings of variables measuring aspects which explain the differences between towns. Taken into account here are 21 variables which are linked with the population size of towns and adjacent areas, altitude, growth rate, population density of surrounding entities and towns, sex ratio, demographic structure, distance from provincial capital and intensity of internal migration. This type of analysis has identified three factors whose most significant correlations are shown in Table 1 . The factors, by order of importance, are: a first factor associated with ageing, with an intense relationship with the variables of the structure; a second factor connected with the phenomenon of emigration; and, finally, a factor defined by proximity to populated spaces. The three factors explain almost 60 per cent of the variance between towns. A score is obtained with regard to each of the factors for every municipality and cluster analysis has then been applied to the scores. These factors configure three rural demographic spaces with results I shall present in the next section.

\section{A DEMOGRAPHIC TYPOLOGY OF RURAL SPACES}

The unequal impacts of ageing, the "un-birth" rate, and scarcity of women in the central areas of the pyramid are essential for interpreting the three typologies being studied (Figure 1).

The first group consisting of 1,463 towns shapes the demographically resilient spaces. These are entities of larger 
size, with a certain demographic stability, at a lower altitude and located on the edge of Spain's central plateau, la Meseta (Figure 2), and also a long way from the more depressed mountain areas. The population densities are higher than the rural average and the sex ratio is slightly greater than that for Spain as a whole. The impact of emigration has been less, and only $60 \%$ of people born in these towns resided in a different town in 2016.

In the second group, 1,622 entities are identified, sharing as their main characteristics high altitude, a small demographic dimension (175 inhabitants on average), an average density of 6.2 inhabitants per $\mathrm{km} 2$, negative growth rates, a significantly higher sex ratio than the first group, a relative level of ageing, a major impact of emigration, and the fact that 80 per cent of people born in these towns now reside in other municipalities. These are rural spaces of emigration.

Finally, the third group consists of rural spaces at risk of irreversible depopulation which could even reach the point of extinction. These are 1,840 entities with characteristics at the extreme end of the scale: maximum altitude, smallest demographic dimension (an average of 110 inhabitants), lowest densities, averaging 4.3 inhabitants per $\mathrm{km} 2$, maximum ageing with average ages close to 60 , and 45 per cent of the inhabitants older than 65 . These are municipalities which have experienced the highest rates of female emigration and also present severe ageing.

Although all three groups are characterized by a gradation of the main demographic indicators, the second and third are closer to those whose indicators mean bad news because, as their demographic structures show, their demographic survival is at stake (Figure 1)

The two latter groups comprise a continuous area in which the country towns with the worst prospects are located: areas surrounding Madrid, especially the Castilla-León region where all the provinces are affected to a greater or lesser degree; Castilla-La Mancha where the situation of demographic unsustainability in the smaller towns of the provinces of Guadalajara and Cuenca is evident; Aragon, where the province of Teruel stands out: and, finally, La Rioja. In contrast, the country towns with the best demographic resilience are found in the provinces located in the Ebro Valley, the space to the south of the line linking Cáceres and Toledo, the Pyrenean zone and the Mediterranean regions. The special settlement pattern of Asturias and Galicia does not allow assessment of the true dimension of demographic problems affecting rural zones in these regions by means of analysing municipal data.

\section{RECENT COMPONENTS OF DEMOGRAPHIC GROWTH IN RURAL SPACES}

FIGURE 2. Spatial location of the typologies of rural municipalities in Spain (2016)

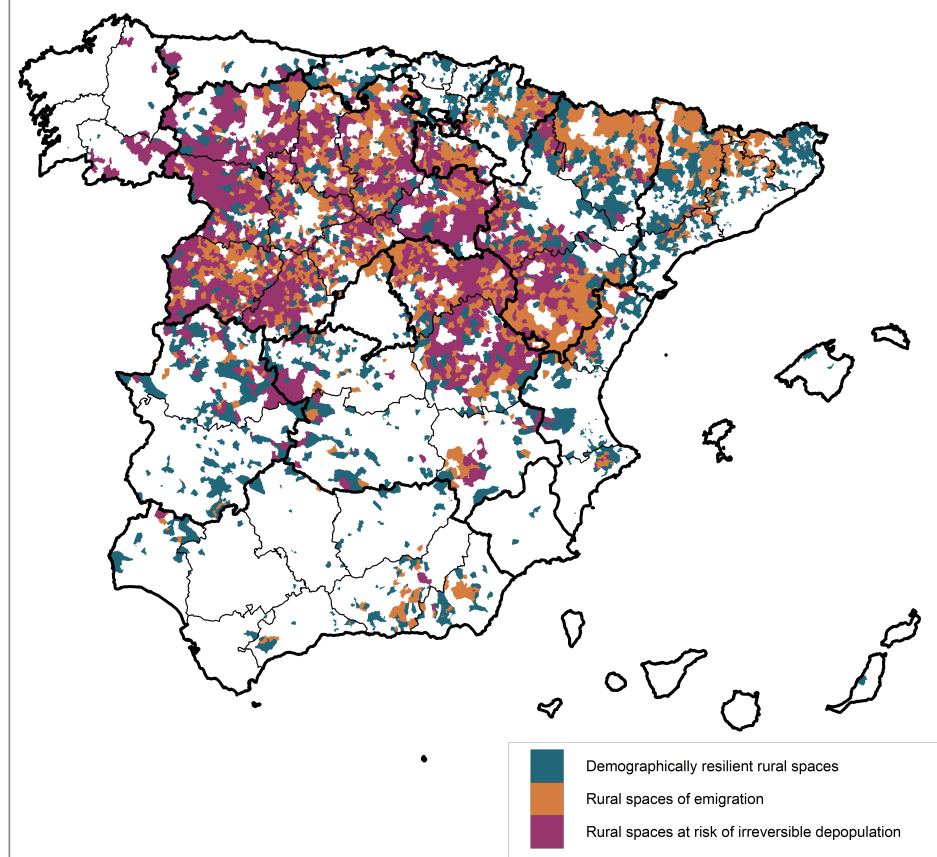

Source: Compiled by author on the basis of microdata from the Official Population 2016.

The last few years have seen considerable changes in the causal demographic factors involved in rural depopulation. Emigration has lost momentum while very low fertility and increased mortality have become more prominent. Then again, while cities have benefitted greatly from the contribution of immigration, its effects in most of Spain's rural areas have been slight. The set of municipalities analysed here has only acquired 1.85 per cent of immigrants, a value which is even lower than their overall presence in Spain's total population (3.1 per cent).

The demographic structures of rural spaces condition their demographic future. The birth rate has been dropping continuously since the mid-1970s while mortality has taken a sustained upwards trend associated with ageing. The towns at risk of irreversible depopulation have the lowest birth rates and highest mortality rates, the lowest natural increase (always negative), the greatest net outward migration within Spain, and the lowest pull-factor levels for foreign immigration. They constitute the extreme case of population decline among the municipalities studied. Groups 1 and 2 show very similar patterns with regard to mortality and migration, but always 
with negative growth overall. In any case, from 1975 to 2015, natural growth in all three groups has been negative every year. The conclusiveness of these data is a palpable sign of the serious problem affecting towns in Empty Spain.

FIGURE 3. Demographic behaviour of rural spaces in Spain (1975-2015)

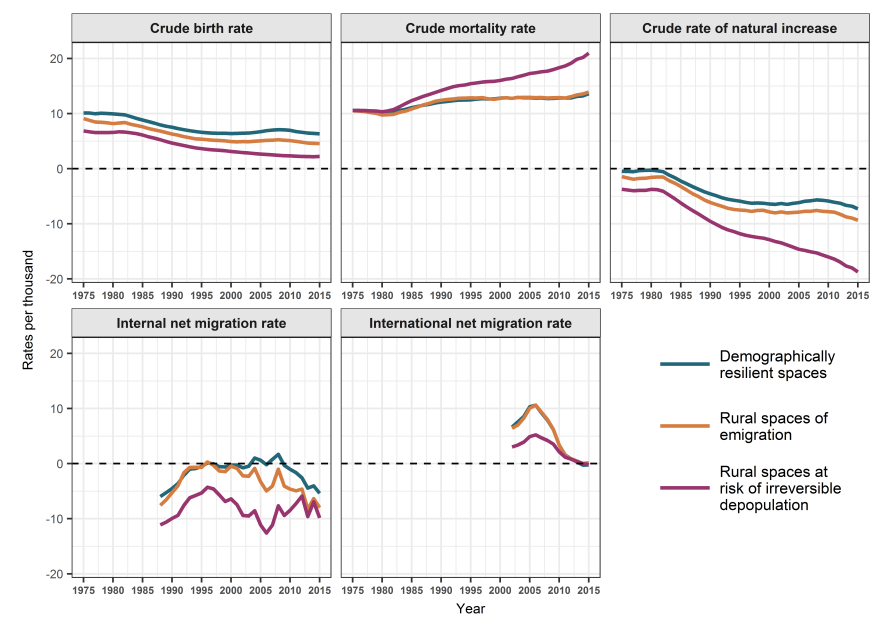

Source: Compiled by author on the basis of Natural Movement of Population (MNP) microdata and population censuses. 5-year moving average.

International immigration has been suggested as a solution to problems of depopulation but it has turned out to be a demographic fata morgana. These may be empty spaces but they have had very little appeal for international immigrants. Furthermore, the figures reveal that a significant number of immigrants from other countries who arrive in the towns with the biggest demographic problems emigrate once more. Between 2000 and 2015, Spanish country towns showed a negative net migration rate for immigrants born in other countries. This result suggests that a first settlement of immigrants in these towns tends to be followed by re-emigration. It is probable that the factors that caused the autochthonous population to leave these rural areas also apply to immigrants.

\section{THE QUEST FOR DEMOGRAPHIC RESILIENCE}

The demographic prospects of rural areas vary considerably in accordance with the geographic sectors described here. In some areas, economic resilience expressed as rural tourism, second homes, and the existence of specific resources linked with the territory can guarantee economic continuity and, to a lesser extent, the maintenance of some population minimums. Nevertheless, most rural centres are not able to retain the few young people who reside in them, especially women, they are not very attractive to potential immigrants, and are also notable for a high circulation of people who do not put down roots in the territory. This immigrant group, the only one which might remedy the lamentable demographic situation, is the key to demographic survival but there will be no sign of any change in this direction unless there is increased public investment in projects that encourage stable settlement of populations in places with demographic problems. Any political intervention must take into account the variety of rural spaces concerned, and should waste no time in making a more precise evaluation of the factors explaining this heterogeneity and, finally, identifying those aspects which might favour demographic and economic resilience.

\section{Sources}

Fundación BBVA and Ivie (Instituto Valenciano de Investigaciones Económicas -). Cambios en la estructura y localización de la población: series homogéneas (1900-2011).

November 2015. Database available online: http://www.fbbva.es/TLFU/ tlfu/esp/areas/econosoc/bbdd/serieshomg.jsp

\section{Bibliographical References}

Collantes, F.; Pinilla, V.; Sáez, L. A. and Silvestre, J. (2014). "Reducing Depopulation in Rural Spain: The Impact of Immigration". Population, Space and Place, 20 (7), 606-621.

Cos, O. de and Reques P. (2005). "Los cambios en los patrones territoriales de la población española (19002001)". Papeles de Economía española, (104), 167-192.
Goerlich, F., Ruiz, F., Chorén, P. and Albert, C. (2015): Cambios en la estructura y localización de la población: Una visión de largo plazo (1842-2011) Bilbao: Fundación BBVA, $354 \mathrm{pp}$

Molino, S. del (2016). La España vacía. Viaje por un país que nunca fue. Madrid, Turner, 296 pp.

Vidal, T. and Recaño, J. (1986). "Rural Demography in Spain Today". Espace, Populations, Sociétés, 4(3), 63-73.

\section{Citation}

Recaño, J. (2017) “The Demographic Sustainability of Empty Spain ”, Perspectives Demogràfiques, $\mathrm{n}^{0} 7, \mathrm{pp}$. $1-4$

Editorial Board

Andreu Domingo and Albert Esteve

\section{Please address correspondence to: Contact}

Joaquín Recaño

jrecano@ced.uab.es

Credits

Graph editing: Anna Turu and

Teresa Menacho

Layout

Xavier Ruiz Vilchez

Centre d'Estudis Demogràfics.

Carrer de Ca n’Altayó, Edifici E2

Universitat Autònoma de Barcelona

08193 Bellaterra / Barcelona

Spain

Telephone: +3493581306o

Email:demog@ced.uab.es

Website: http://ced.uab.es/en/

URL

http://ced.uab.es/en/difussion/

butlleti-perspectives-demografiques/ 